\title{
Patent Quality and Pro-patent Policy
}

\author{
Koki Arai'
}

\begin{abstract}
This paper analyzes the patent examination and litigation process in terms of a simple Perfect Bayesian Equilibrium model, and interprets the results in line with real pro-patent trends in the US and other countries. Each country's pro-patent policy option is different from the other because of reflecting its own path-dependent patent situation. That is, when a country adopts an easy patent policy (a pro-patent policy), firms in the country gain larger payoffs in the short term. Hence, every country seeks to adopt an easy patent policy. However, the easy patent policy undermines the true invention incentive. In this situation, it is difficult for any country to escape the problem, depending on the historical inertia.
\end{abstract}

Keywords: patent quality; Perfect Bayesian Equilibrium; pro-patent policy.

I Competition Policy Research Center (CPRC), and Economic Research Office, Japan Fair Trade Commission, I-I I Kasumigaseki, Chiyoda-ku, Tokyo, Japan. Tel. +8I-47-353-9I22. Email: koki.arai@nifty.ne.jp 


\section{Introduction}

Recently, many arguments have been put forward for an intellectual property system that seeks a following propatent policy. Regarding the process of pursuing a patent, the Federal Trade Commission (2003) and the National Academy of Sciences (2004) are concerned about problems regarding the low level of patents without any link to innovation in the US. The Economic Report of the President of the Council of Economic Advisers pointed out the necessity for sufficient patent granting to generate broader patent protection than copyright or other intellectual properties. Regarding the process of implementing patents, excessive lawsuits are considered a problem given the extremely high legal costs, long court terms, the increasing number of patent lawsuits, extremely expensive damages or settlement packages, and patent tolls. For example, the extremely high legal costs (costs to both the plaintiff and defendant average US\$4 million in patent lawsuits), long court terms (average invalid fixed terms are 12 years: 8.5 years for initiating the lawsuit and 3.5 years for disputing the patent), increasing number of patent lawsuits ( 1.5 times more than existed 10 years ago), and extremely expensive damages or settlement packages (US\$909.5 million: Polaroid vs. Kodak [1990]; US\$612.5 million: NTP vs. RIM [2006]).

This situation is described by Lemley and Shapiro (2005), who state that economists increasingly recognize that a patent does not confer upon its owner the right to exclude, but rather a right to try to exclude, by asserting the patent in court (see also Shapiro 2003).

Lemley (200I) suggests that strengthening the examination process of the Patent and Trademark Office (PTO) is not cost-effective, and that society would be better off spending its resources on a judicial inquiry into the validity of the few cases in which the examination process matters than paying for a more protracted examination of all patents ex ante. The key fact is that very few patents are actually litigated or licensed; most of them simply sit on a shelf unused, or are used only for noncontroversial purposes like financing.

Chiou (2008) explains and extends this discussion by using Perfect Bayesian Equilibrium (PBE) to argue that when the patent holder has private information about the patent's validity, a weak patent is more likely to be settled and escape court challenges than a strong patent. When the economy is suffering from a low-patent-quality problem, a tighter examination by the patent office may strengthen private scrutiny over a weak patent.

Farrell and Shapiro (2008) studied probabilistic patents, and concluded that weak patents licensed to downstream firms that are not rivals command correspondingly low royalties. On the other hand, weak patents on technology used by downstream firms that are rivals command large running royalties. Therefore, they suggest a targeted approach that involves the reexamination of issued patents covering valuable technology that is useful to multiple downstream firms competing against each other or against the patent holder.

In this light, we consider a model based on Chiou's idea of arranging the PTO's function of quality control of patents and then discuss the perspectives of the longterm and international context.

\section{The Model}

There are three players: An inventor $A$ (she) seeks patent protection for her invention, which, if an application is filed, is examined by the patent office and possibly by a private challenger $B$ (he) in court to verify whether the invention fulfills the patentability requirements specified in the patent law.

Suppose that A's patent has two types of patent invalidity: low invalidity type and high invalidity type. The low invalidity type patent has a low probability $(x)$ of losing its patent litigation, while the high type has a high probability ( $h x: h>1$ ) of losing litigation. This is A's private information, so $A$ herself knows the type (good or bad), but $B$ does not. $B$ has a common initial belief, $\operatorname{Pr}(x)=y$. Implicit in this assumption is that all the stages of the invention are complete, so that what happens at the patent examination stage has no impact on the composition of the two types of inventor. 


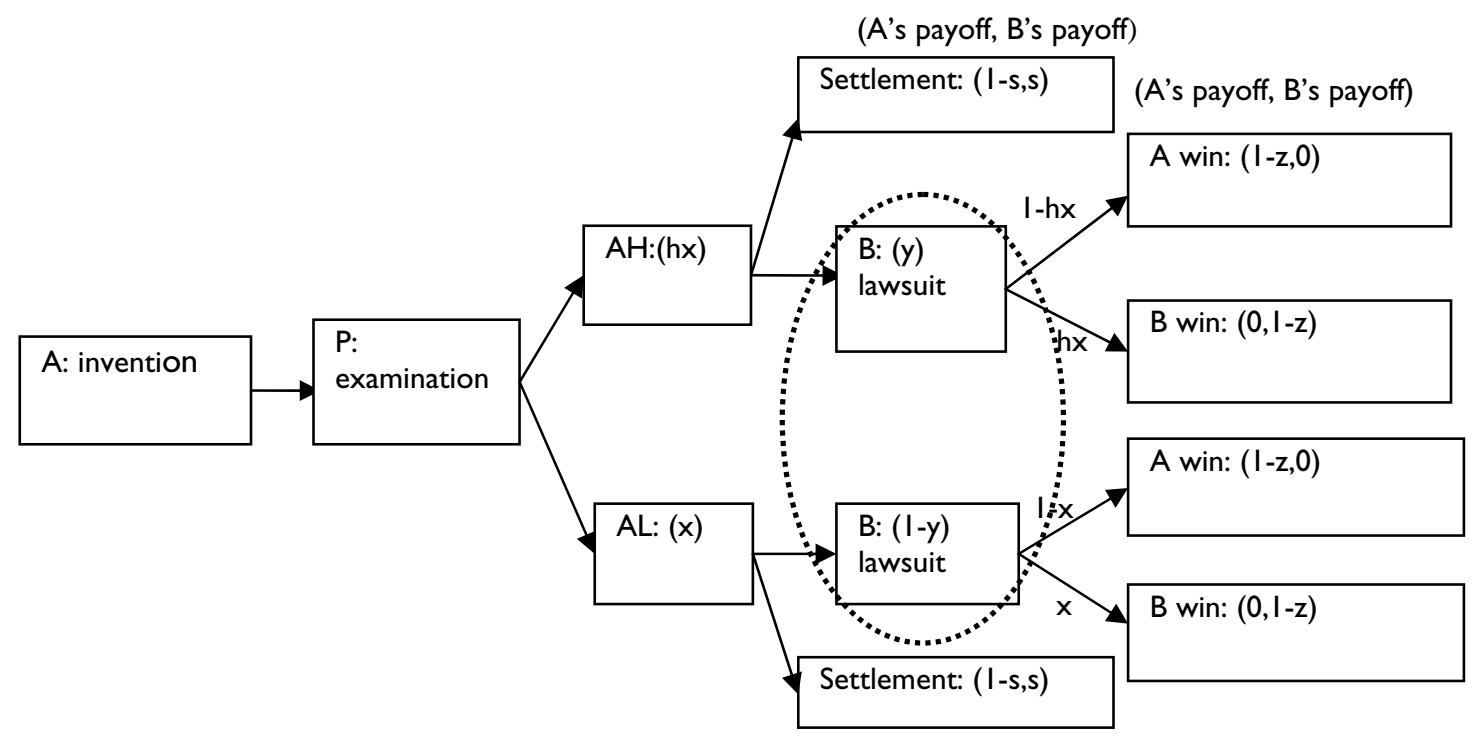

Figure I. Model

The timing is as follows. First, $A$ creates an invention, and then she goes to the patent office to seek a patent. Next, the PTO grants a patent based on its patent policy. Then, $B$ starts a litigation related to the patent validity. In the case of a patent challenge, $A$ can negotiate with $B$ before or after the litigation starts. We assume that, when bargaining, $A$ makes a take-it-or-leave-it offer to $B$. If there is no settlement, the court makes a judgment based on the probability $(x$ or $h x)$.

When the patent is implemented, $A$ will have I (payoff). If $B$ wins the patent invalid lawsuit, then the payoff will be transferred from $A$ to $B$ after taking away the litigation costs $(z)$. We do not consider the contingent fee.

Based on his belief, $B$ has an expected payoff of $\{y h x+(I-$ y) $x\}(I-z): \pi_{B}$. Then, after $B$ brings the lawsuit, $A$, with private information, has an expected payoff: $(1-x)(1-z)$ : $\pi_{A}^{L}$, and $(I-h x)(I-z): \pi_{A}^{H}$. Note that $\pi_{A}^{H}<\pi_{A}^{L}$, which is due to $x<h x$.

We consider the range of after-litigation costs in comparison with the previous expected payoff in this framework. The litigation process, which includes a patent validation lawsuit, always bears a heavy burden for the defendant. Therefore, before initiation of the lawsuit, if $A$ takes into consideration both B's expected payoff and her own litigation costs, then $A$ makes a settlement under the following conditions:
Firstly, if the litigation costs are too high to justify a litigation process, then $A$ pays $B$ a settlement charge (s); that is, something minimal, but more than $B$ 's expected payoff:

$(1-x)(1-z)<1-([y h x+(1-y) x](1-z)+s)$.

The range of the litigation cost is unequal to (I) (hereinafter, something minimal $s$ is omitted):

$$
\frac{y(h-1) x}{y(h-1) x+1}<z
$$

Secondly, if litigation costs are not high enough for good $A$ to take litigation action, and high enough for bad $A$ to give up the litigation process, then good $A$ takes litigation and bad $A$ makes a settlement. Good $A$ knows there is a high probability of winning and expects the good payoff after the litigation under reasonable litigation costs, while bad $A$ has no choice but to make a settlement because she is also aware of her own payoff and her heavy litigation costs:

$(1-h x)(1-z)<1-[y h x+(1-y) x](1-z) \leq(1-x)(1-z)$.

The range is as follows (2):

$$
\frac{(1-y)(h-1) x}{1-(1-y)(h-1) x}<z \leq \frac{y(h-1) x}{y(h-1) x+1} \text {. }
$$


Thirdly, if litigation costs are not high for either good or bad $A$, then $A$ takes the litigation process, and states ( $I$ ) through (3) occur:

$$
1-[y h x+(1-y) x](1-z) \leq(1-h x)(1-z) .
$$

This range is as follows (3):

$$
z \leq \frac{(1-y)(h-1) x}{1-(1-y)(h-1) x}
$$

Therefore, if the value of $z$ is in situation (I), then $A$ makes a settlement with $B$ before the litigation. If $z$ is in situation (2), then good $A$ takes litigation but bad $A$ makes a settlement. If $z$ is situation (3), then both good and bad $A$ take litigation, and we subsequently have the following situations. In particular, we focus on the (3) situation.

We use the Perfect Bayesian equilibrium (PBE) to determine B's action and A's response.

In turn, we consider the last phase of the litigation after all the court processes.

If $A$ knows that her payoff is more than B's expected payoff, then $A$ can pay $B$ 's expected payoff plus a nominal amount to avoid a risky and costly decision. $B$ accepts the offer because it is more than B's expected payoff. This situation is derived from the following condition: $\left(\pi_{B}<\right.$ $\left.\pi_{A}^{H}<\pi_{A}^{L}\right)$

$$
\begin{aligned}
& {[y h x+(1-y) x](1-z)<(1-h x)(1-z),} \\
& y<\frac{1-(h+1) x}{(h-1) x}
\end{aligned}
$$

In this situation (4), we have a pooling equilibrium ( $A$ offers a settlement, then $B$ accepts it).

$$
(A, B)=(I-[y h x+(I-y) x](I-z),[y h x+(I-y) x](I-z))
$$

Due to (I), substitute $y=\frac{1-(h+1) x}{(h-1) x}-\varepsilon$ for the above payoff, and we obtain $(A, B)$ as follows:
$(A, \quad B)=(z-x \epsilon+x z \epsilon-h x(-1+z)(1+$

$\epsilon),-(-1+z)(1-x \epsilon+h x(1+\epsilon)))$

In the payoff of (5), A's payoff increases in $h\left(\frac{\partial A}{\partial h}=\right.$ $-x(-1+z)(1+\epsilon)>0$, when $x>z)$.

If $B$ 's expected payoff is between $A H$ 's and $A L$ 's expected payoffs, then $A L$ hopes to pay $B$ a compensated payoff in order to come to a settlement, but $A H$ cannot. If $A$ offers $B$ compensation, then $B$ accepts the payoff plus something minimal. This comes because of the following condition: ( $\pi_{A}^{H}<\pi_{B}<\pi_{A}^{L}$ )

$$
\begin{gathered}
(1-h x)(1-z)<[y h x+(1-y) x](1-z) \leq(1-x)(1-z) \\
\frac{1-(h+1) x}{(h-1) x} \leq y<\frac{1-2 x}{(h-1) x}
\end{gathered}
$$

In this situation (6), we have a separate equilibrium: $A L$ offers a settlement, but $A H$ does not. If $B$ has the offer, then $B$ accepts it $(y=0$, due to PBE), $B$ 's payoff is $(1-x)(1-z)+\varepsilon$.

$(A, \quad B)=\left(\frac{1+\mathrm{h}+\mathrm{x}(-1+\mathrm{z})+\mathrm{h}^{2} \mathrm{x}(-1+\mathrm{z})-\mathrm{hz}-\epsilon}{1+\mathrm{h}}, \frac{x-x \mathrm{z}+\epsilon+h(\mathrm{hx}-\mathrm{hxz}+\epsilon)}{1+h}\right)$

In the payoff of (7), under $0<x<1$, A's payoff increases in $h\left(\frac{\partial A}{\partial h}<0\right)$.

If B's expected payoff is larger than A's expected payoff, then $A$ cannot afford to avoid $B$ 's lawsuit, as represented by the following condition: $\left(\pi_{A}^{H}<\pi_{A}^{L}<\pi_{B}\right)$

$$
\begin{aligned}
& (1-x)(1-z) \leq[y h x+(1-y) x](1-z), \\
& \frac{1-2 x}{(h-1) x} \leq y .
\end{aligned}
$$

Under (8), we have another pooling equilibrium. (A does not offer a settlement.)

$(A, B)=\left(\frac{\left(-1-\mathrm{h}+\mathrm{x}+\mathrm{h}^{2} \mathrm{x}\right)(-1+\mathrm{z})}{1+\mathrm{h}}, \frac{\left(1+h^{2}\right) x(1-z)}{1+h}\right)$ 
In the payoff of (9), A's payoff $\left(\frac{\left(1+h-x-h^{2} x\right)(1-z)}{1+h}\right)$ decreases in $h\left(\frac{\partial A}{\partial h}<0\right)$.

\section{Discussion}

\section{Interpretation of the Model}

Based on this analysis, we can consider the situation of the inventor and the PTO among countries. We assume that once the PTO strengthens the patent examination, $h$ will decrease because strict patent examination produces accurate and nonfluctuating patents.

Given a specific value of $x$ and $y$ (fixed innovation ratio in the short term), if $h$ decreases (increases), then A's payoff will increase (decrease) in situations (5), (7), and (9).

We can apply the above analysis (6) and (8) to Lemley's discussion of the US problem. There are a number of weak patents, and strengthening the PTO's examination leads to decreasing an inventor's incentive ( $h$ goes down; A's payoff goes up).

The aggregate number of applications and grant of patents shows the policy change (see Table I). We estimate the relationship between the number of US patent grants per year (USGR) and the number of US patent applications per year (USAPP) with around a 2005 patent policy change (USAPPDUMMY2005: USAPP multiply dummy variable; that is, 0 before 2004 and I after 2005) from pro-patent to marginally strict examination. ${ }^{2}$ The reduced formed estimation equation is as follows:

USGR $=a_{1}+a_{2}$ USAPP $+a_{3}$ USAPPDUMMY2005 $+\varepsilon_{1}$

The result of the estimation shows that the number of applications has significant positive impact on the number of grants $\left(a_{2}\right)$, and significant negative impact on the USAPPDUMMY2005 $\left(a_{3}\right)$. Although the estimation is simple and does not eliminate bias, for example, serial correlation cannot identify but is doubtful, we can capture the change from the pro-patent policy trend.

On the other hand, the analysis (4) can describe the Japanese patent situation. There is an atmosphere that the PTO's examination is reliable. (See the ratio of patent

\footnotetext{
${ }^{2}$ See US PTO The $21^{\text {st }}$ Century Strategic Plan (2003).
}

invalidation: First Japanese PTO, second US PTO; 95\%, First US PTO, second Japanese PTO; 59\%, Yasuda [2010], see also Takakura [2008].) In this situation, weakening the examination provokes an inventor's incentive ( $h$ goes up; A's payoff goes up).

In a similar way, we estimate the relationship between the number of Japanese patent grants per year (JPGR) and the number of Japanese patent applications per year (JPAPP) with around a 1995 patent policy change (JPAPPDUMMY1995: JPAPP multiply dummy variable; that is, 0 before 1994 and I after 1995) from strict patent examination to pro-patent. ${ }^{3}$ The reduced formed estimation equation is as follows:

$\mathrm{JPGR}=b_{1}+b_{2} \mathrm{JPAPP}+b_{3} \mathrm{JPAPPDUMMY} 1995+\varepsilon_{2}$

The result of the estimation shows that the number of applications has significant positive impact on the number of grants $\left(b_{1}\right)$, and also significant positive impact on the JPAPPDUMMY2005 $\left(b_{2}\right)$. Although the estimation is simple and does not eliminate bias, we can see the change to propatent policy trend.

When we consider the litigation cost $(z)$ before and after, if $h$ decreases (increases), then the range of $z$ in (2) will be greater (smaller). This indicates that if the PTO strengthens the patent examination, then the litigation will decrease because necessary litigation costs are increasing. Thus, the PTO's strict examination can lead to a crowdingout effect of the patent litigation under the specific high litigation cost condition.

This implies the relationship between the litigation mechanism and the examination policy of patents. It seems that the pro-patent policy discussion in several countries simultaneously and adversely in the 2000s has had an effect. In order to implement the pro-patent policy, there was great discussion how to strengthen the patent examination in the US. In contrast, relaxation of patent examination has provoked a great deal of discussion in Japan.

Let us turn to the problem of research and development (R\&D) of patents in terms of quality or quantity.

${ }^{3}$ See Policy Committee on Innovation and Intellectual Property of Japan Patent Office (2008). 
Dependent Variable: USGR

Method: Least Squares

Sample: 195I 2008

Included observations: 58

\begin{tabular}{ccccc}
\hline \hline Variable & Coefficient & Std. Error & t-Statistic & Prob. \\
\hline \hline C & 15971.32 & 2568.429 & 6.218320 & 0.0000 \\
USAPP & 0.455311 & 0.016122 & 28.24124 & 0.0000 \\
USAPPDUMMY2005 & -0.127054 & 0.015560 & -8.165162 & 0.0000 \\
\hline \hline R-squared & 0.951133 & Mean dependent var & 84676.71 \\
Adjusted R-squared & 0.949356 & S.D. dependent var & 41031.29 \\
S.E. of regression & 9233.767 & Akaike info criterion & 21.14946 \\
Sum squared resid & $4.69 \mathrm{E}+09$ & Schwarz criterion & 21.25603 \\
Log likelihood & -610.3343 & Hannan-Quinn criter. & 21.19097 \\
F-statistic & 535.2524 & Durbin-Watson stat & 1.075473 \\
Prob(F-statistic) & 0.000000 & & \\
\hline \hline
\end{tabular}

Table I. Source: WIPO patent application filings, and patents granted http://www.wipo.int/ipstats/en/statistics/patents/

Dependent Variable: JPGR

Method: Least Squares

Sample: 195I 2008

Included observations: 58

\begin{tabular}{lrlll}
\hline \hline \multicolumn{1}{c}{ Variable } & Coefficient & Std. Error & t-Statistic & Prob. \\
\hline \hline \multicolumn{1}{c}{ C } & 9457.035 & 4575.970 & 2.066673 & 0.0435 \\
JPAPP & 0.172745 & 0.022969 & 7.520744 & 0.0000 \\
JPAPPDUMMY1995 & 0.149922 & 0.019288 & 7.772630 & 0.0000 \\
\hline \hline R-squared & 0.883342 & Mean dependent var & 62308.34 \\
Adjusted R-squared & 0.879099 & S.D. dependent var & 51165.07 \\
S.E. of regression & 17790.48 & Akaike info criterion & 22.46105 \\
Sum squared resid & $1.74 E+10$ & Schwarz criterion & 22.56763 \\
Log likelihood & -648.3705 & Hannan-Quinn criter. & 22.50257 \\
F-statistic & 208.2309 & Durbin-Watson stat & 1.432215 \\
Prob(F-statistic) & 0.000000 & & \\
Prob(5) & & & \\
\hline \hline
\end{tabular}

Table 2. Source: WIPO patent application filings, and patents granted http://www.wipo.int/ipstats/en/statistics/patents/ 


\section{Historical Pro-patent Policy and Its International Implications}

The mechanism of diffusion of the pro-patent policy does not consist only of the countermeasures of the governmental patent policy. We can understand the propatent policy in terms of the international situation and innovation enhancement.

We outlined the recent actual trend of patent policy in section I above. The US had adopted a pro-patent policy in the late 1980s, before the problems mentioned in section I came to the US. The policy made $h$ increase and $y$ decrease; then A's payoff increased at that time. The policy made the US full of low-quality patents to obtain a larger payoff for an inventor in the short term. On the other hand, from the viewpoint of high-quality patents for true innovation, there was less innovation by bad invention; that is, high $h$ undermines true invention, $x$. The US has faced this problem and sought to take measures to initiate or revive true inventions.

As a countermeasure for this business climate in relation to patents, the EU and Japan wished to start to adopt a pro-patent policy following the US. In this regard, the EU and Japan considered the problem that faced the US, and they are challenging new policy-building strategies such as improving the process of perusing patents or a proinnovation policy based on the US experiences and their own history (Figure 2).

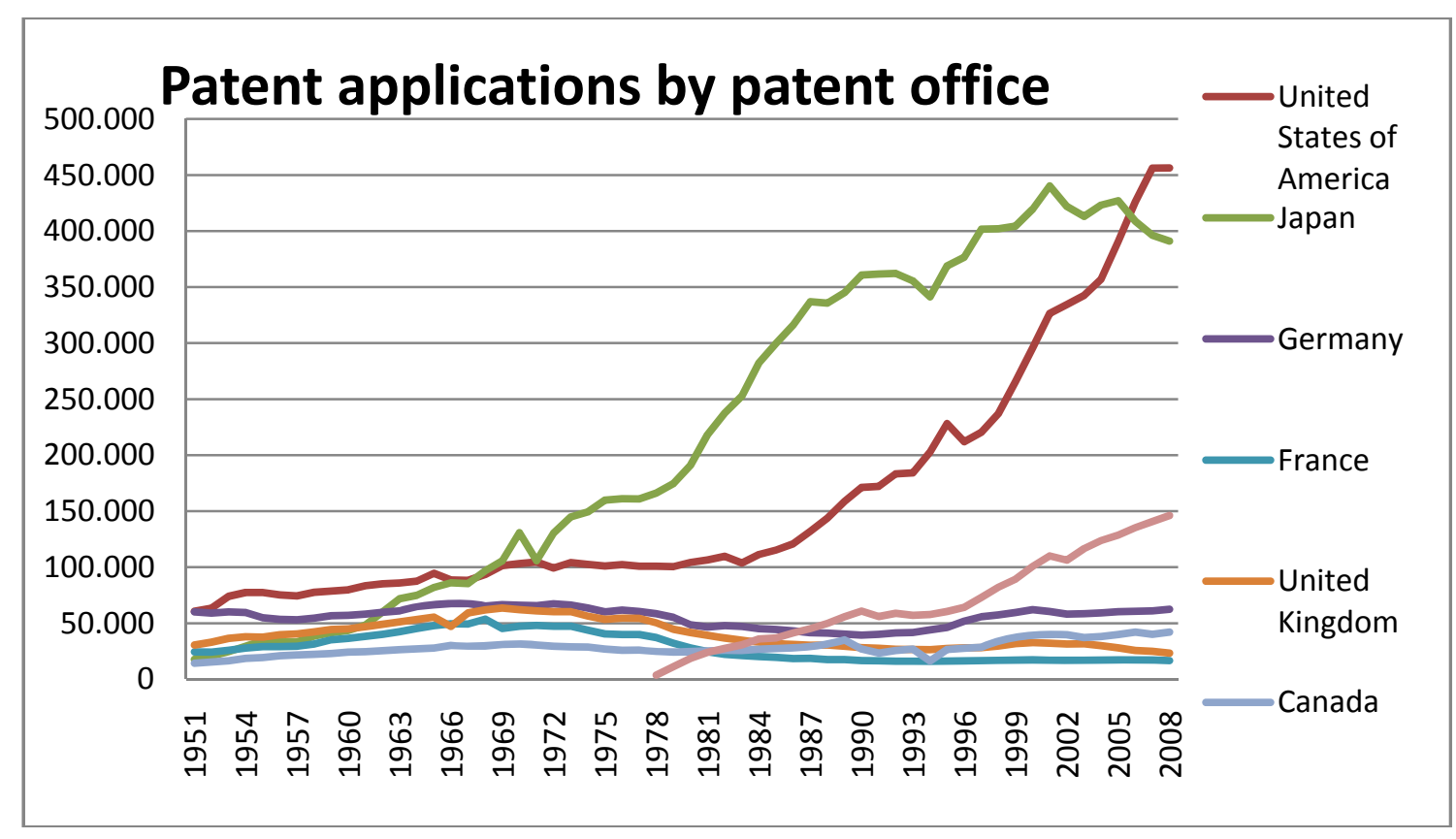




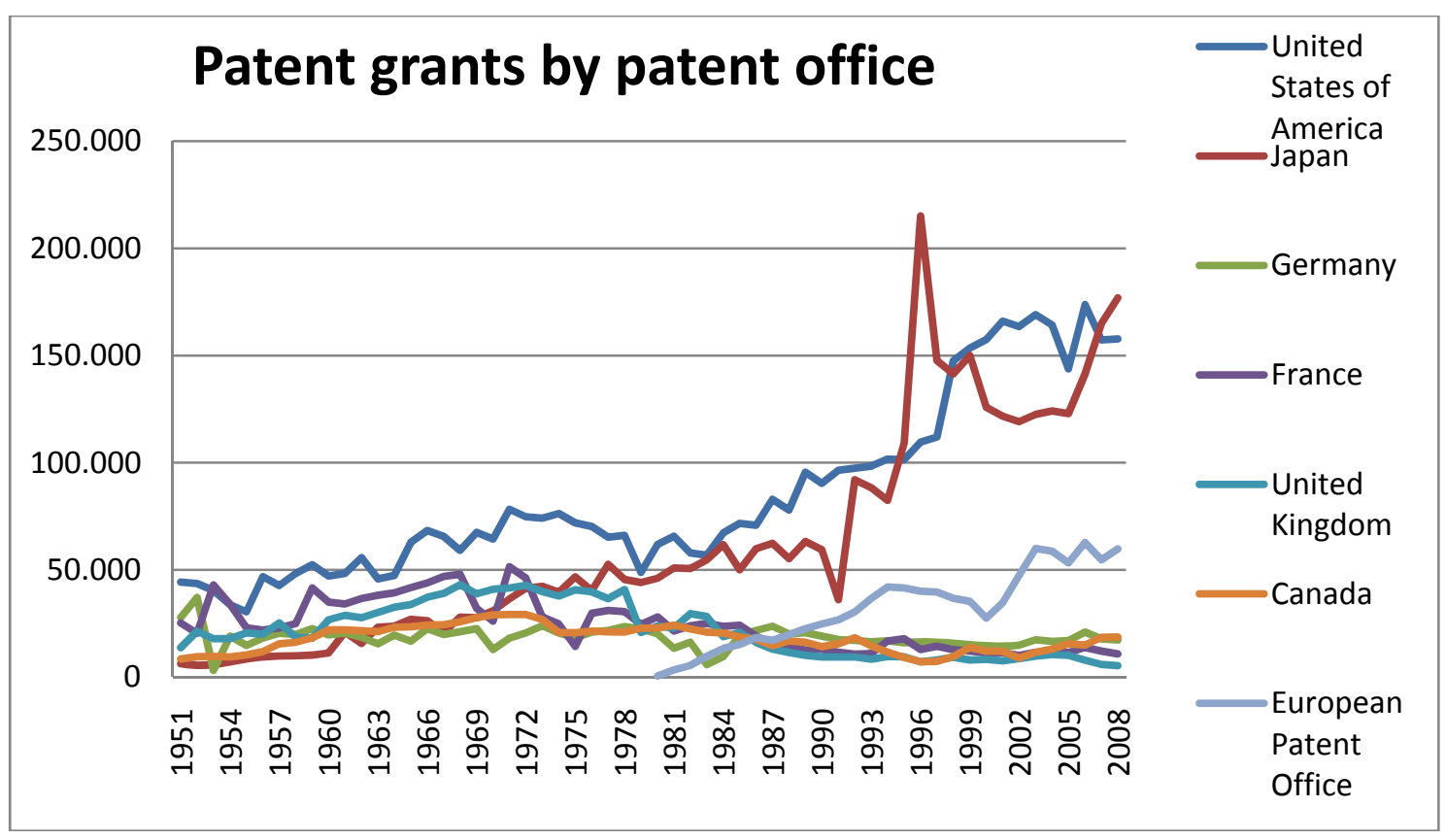

Figura 2. Source: WIPO patent application filings, and patents granted. http://www.wipo.int/ipstats/en/statistics/patents/

\section{Concluding Remarks}

This paper analyzed the patent examination and litigation process in terms of a simple model, and interpreted the results in line with real patent trends and the international context between the US and other economies. Each country's pro-patent policy option is different from the other because of reflecting its own path-dependent patent situation.

That is, when a country adopts an easy patent policy (a pro-patent policy), firms in the country gain larger payoffs in the short term. Hence, every country seeks to adopt an easy patent policy. However, the easy patent policy undermines the true invention incentive. In this situation, it is difficult for any country to escape the problem, depending on the historical inertia.

A few economic contributions have started to devise a theoretical framework for the PTO's overload problem (Caillaud and Duchene, 2010), and it would be interesting to investigate how this policy change that we have analyzed would be affected in a patent protection endogenous context. Another future analysis will involve widely empirical research using this simple model in terms of the different fields of patents and the comparative international situation. Based on this analytical and empirical study, we can contribute to a discussion of improvements of patent policy as well as its system design or litigation process.

\section{Acknowledgments}

The author wishes to thank Yasushi Kudo, Tomomichi Mizuno and Jing-Yuan Chiou for useful comments on earlier drafts. The views expressed in this paper are those of the authors and do not necessarily represent the views of the Japan Fair Trade Commission or any organizations.

\section{References}

CAILlAUD, B., Duchene, A. (2010). Patent Office in Innovation Policy: Nobody's Perfect, International Journal of Industrial Organization, forthcoming.

CHIOU, J.-Y. (2008). The Patent Quality Control Process: Can We Afford An (Rationally) Ignorant Patent Office? SSRN: http://ssrn.com/abstract $=1099948 \quad$ [Accessed I2/I I/20I0].

FARRELL, J., Shapiro C. (2008). How strong are weak patents? American Economic Review 98, I347-1369. 
FEDERAL TRADE COMMISSION (2003). To Promote Innovation: A Proper Balance of Competition and Patent Law and Policy.

LEMLEY, M. (200I). Rational ignorance at the patent office, Northwestern University Law Review 95, I495-1529.

LEMLEY, M., Shapiro C. (2005). Probabilistic patents, Journal of Economic Perspectives 19, 75-98.

NATIONAL ACADEMY OF SCIENCES (2004). A Patent System for the $21^{\text {st }}$ Century.

Policy Committee on Innovation and Intellectual Property of Japan Patent Office (2008) New Intellectual Property Policy for Pro-Innovation - Intellectual Property System as Global Infrastructure-.

SHAPIRO, C. (2003). Antitrust Limits to Patent Settlements, RAND Journal of Economics 34, 39 I-4II.

TAKAKURA, S. (2008). Review of the Recent Trend in Patent Litigation from the Viewpoint of Innovation, http://www.rieti.go.jp/en/columns/a0l 0242.html

[Accessed 12/11/2010].

UNITED STATES PATENT AND TRADEMARK OFFICE (2003). The $2 \mathrm{I}^{\text {st }}$ Century Strategic Plan, http://www.uspto.gov/web/offices/com/strat2l/index.htm

YASUDA, F. (2010). Outline of Patent Prosecution Highway, (in Japanese), http://www.jpo.go.jp/torikumi/t torikumi/pdf/highway user seminar/ipo happyo.pdf [Accessed I2/II/2010]. 